\title{
Autotransplantation donor tooth site harvesting using piezosurgery
}

\begin{tabular}{l}
\hline Access this article online \\
\hline Website: \\
www.amsjournal.com \\
\hline DOI: \\
10.4103/2231-0746.186137 \\
\hline Quick Response Code: \\
\end{tabular}

\author{
Leena P. Ylikontiola', George K. Sándor ${ }^{1,2}$ \\ ${ }^{1}$ Department of Oral and Maxillofacial Surgery, Medical Research Center, Oulu University Hospital, \\ Institute of Dentistry, University of Oulu, Oulu, ${ }^{2}$ BioMediTech, Institute of Bioscience and \\ Technology, University of Tampere, Tampere, Finland
}

Address for correspondence: Dr. Leena P. Ylikontiola, University of Oulu, Aapistie 5A, Office No: 2126B, 90014 Oulu, Finland. E-mail: leena.ylikontiola@oulu.fi

\section{ABSTRACT}

Background: The harvesting of a tooth as a candidate for tooth autotransplantation requires that the delicate dental tissues around the tooth be minimally traumatized. This is especially so for the periradicular tissues of the tooth root and the follicular tissues surrounding the crown. The aim of this report is to describe the use of piezosurgery as an attempt at morbidity reduction in the harvesting of teeth for autotransplantation. Methods: A piezosurgical handpiece and its selection of tips were easily adapted to allow the harvesting and delivery of teeth for autotransplantation purposes. Results: Twenty premolar teeth were harvested using a piezosurgical device. The harvested teeth were subsequently successfully autotransplanted. All twenty teeth healed in a satisfactory manner without excessive mobility or ankyloses. Conclusions: Piezosurgery avoids some of the traumatic aspects of harvesting teeth and removing bone which are associated with thermal damage from the use of conventional rotary instruments or saws. Piezosurgery can be adapted to facilitate the predictable harvesting of teeth for autotransplantation purposes.

Keywords: Autotransplantation, piezosurgery, tooth harvest

\section{INTRODUCTION}

To ensure that a harvested tooth remains a viable candidate for tooth autotransplantation, the delicate stem cell containing dental tissues which surround the developing tooth must be minimally traumatized. ${ }^{[1-3]}$ This includes the still developing periradicular and pericoronal tissues of the harvested tooth. [3] Piezosurgery has been reported to generate far less heat than conventional surgical instruments such as rotary drills or saws of varying types. ${ }^{[4]}$ Piezosurgery has been successfully applied and adapted to routine intraoral use in many surgical procedures performed by maxillofacial surgeons. ${ }^{[4,5]}$ These piezosurgical procedures include surgical tooth removals in close proximity to vital structures such as nerves and vessels, sinus floor elevation procedures, ${ }^{[5-7]}$ cranial and maxillofacial osteotomies, ${ }^{[8,9]}$ and harvesting autogenous bone grafts from the iliac crest with the goal of reducing morbidity at the donor site.
Potential candidate autotransplant donor teeth are often severely ectopically positioned and may require a considerable amount of potentially heat generating alveolar bone drilling to allow the removal or delivery of the tooth. Piezosurgery is known to minimize local heat production when compared to conventional surgical devices such as rotary drills, reciprocating, or oscillating saws for example. ${ }^{[10]}$ This study aimed to adapt piezosurgery to the donor site harvesting of unerupted permanent premolar teeth for autotransplantation purposes in the jaws.

This is an open access article distributed under the terms of the Creative Commons Attribution-NonCommercial-ShareAlike 3.0 License, which allows others to remix, tweak, and build upon the work non-commercially, as long as the author is credited and the new creations are licensed under the identical terms.

For reprints contact: reprints@medknow.com

Cite this article as: Ylikontiola LP, Sándor GK. Autotransplantation donor tooth site harvesting using piezosurgery. Ann Maxillofac Surg 2016;6:75-7. 


\section{METHODS}

This pilot study population consisted of twenty permanent maxillary or mandibular premolar teeth which were morphologically sound, with sufficient crown and root development, with intact dental follicles. These teeth were designated as potential candidate teeth for autotransplantation by a team of multidisciplinary surgical, orthodontic and pediatric dental consultants.

The principles of harvesting of the autotransplanted donor tooth began with the removal of the overlying deciduous tooth to allow access to the donor tooth. The alveolar bone surrounding the intact dental follicle of the autotransplanted donor tooth was removed using a piezosurgical device with copious irrigation. Bone removal was complete once sufficient alveolar bone had been removed from the pericoronal region of each unerupted autotransplant donor tooth [Figure 1] to allow atraumatic delivery of the tooth with its intact dental follicle [Figure 2] and intact apical papilla tissues [Figure 3]. The donor teeth were mobilized, delivered, and then left in their native alveolar sockets until the moment that their recipient sites were ready to receive them. The

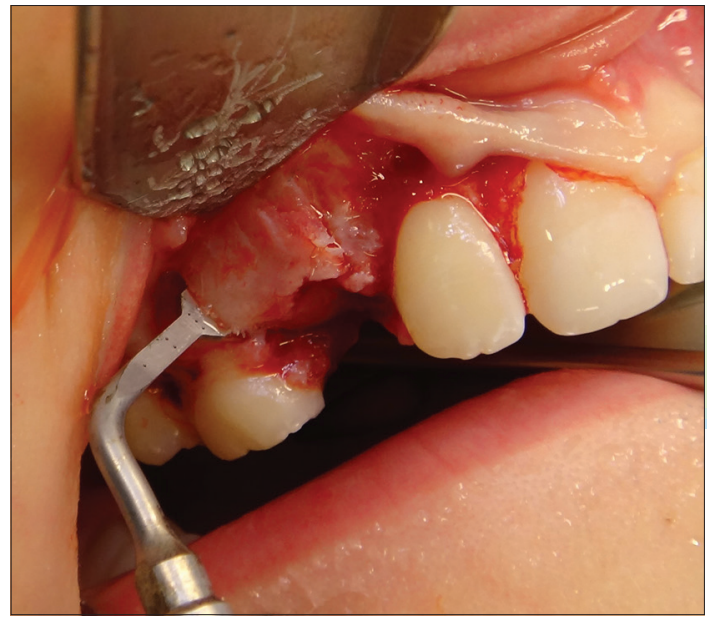

Figure 1: Piezo-surgical tip removing bone near the coronal aspect of donor tooth 14 which is being harvested for autotransplantation purposes

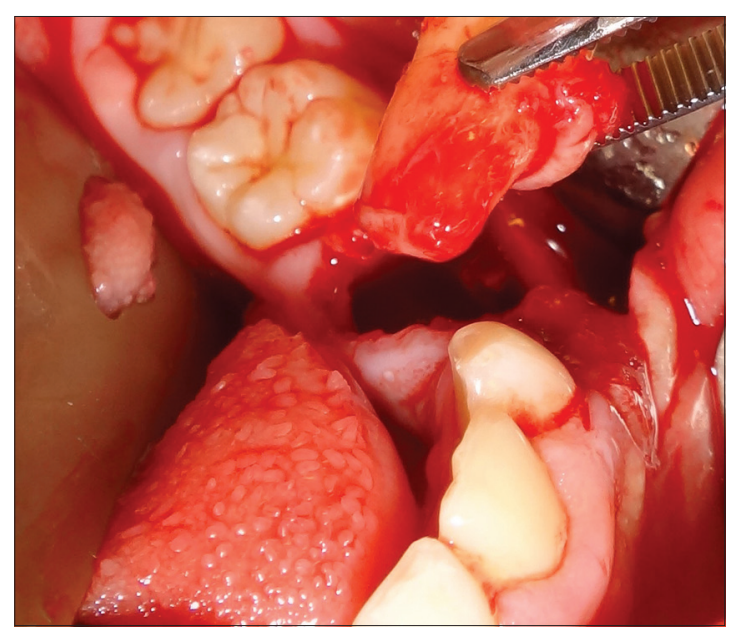

Figure 3: Tooth harvested for autotransplantation showing intact peri-radicular and apical papilla tissues autotransplanted teeth were handled only at their coronal aspects by exclusively lightly handling the tooth with forceps occlusal to the cementoenamel junction. The peri-radicular tissues were preferably not handled with forceps, and the tissues of the developing apical papilla were always left untouched. This was especially important to avoid damage to the periodontium of the donor teeth which was considered to be an essential requirement for postoperative wound healing of the donor tooth at the recipient site.

The postoperative progress of the transplanted teeth was followed clinically and radiographically over the next 12 months [Figure 4].

\section{RESULTS}

All twenty transplanted teeth were delivered with their follicles and apical papilla tissues intact. The transplanted teeth healed in a satisfactory manner without either excessive mobility or ankylosis. Although the root lengths were variable, all twenty teeth were morphologically intact and clinically sound.

\section{DISCUSSION}

Tooth autotransplantation is dependent on the atraumatic harvesting of donor teeth. ${ }^{[1,2]}$ The developing dental tissues require gentle manipulation with a minimum of thermal damage due to excessive heat production at the time of tooth

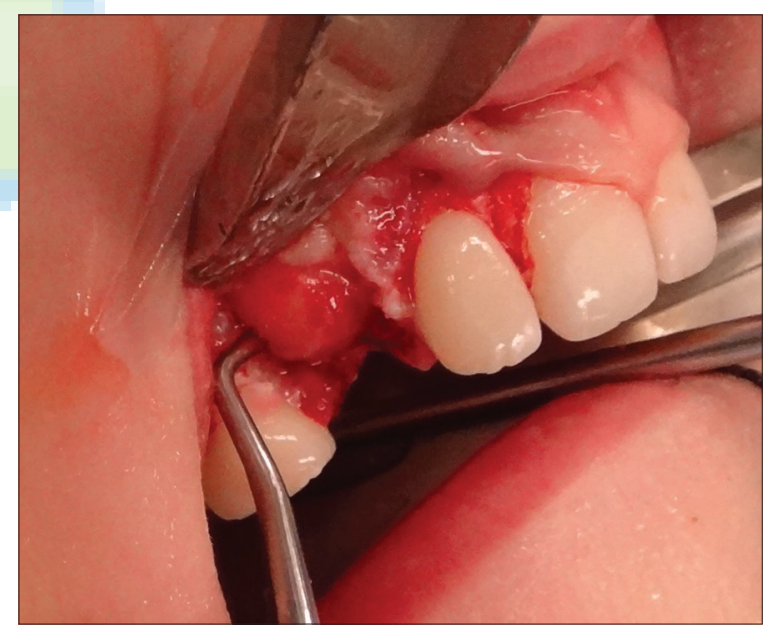

Figure 2: Peri-coronal bone removal using a piezo-surgical handpiece with an intact follicle surrounding the crown of tooth 14

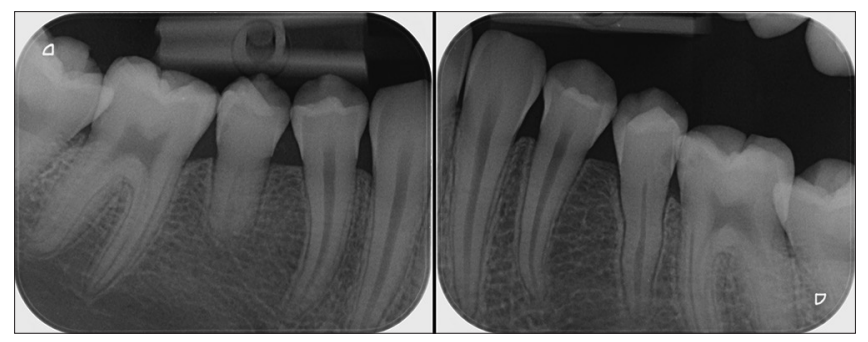

Figure 4: Periapical radiographs taken 18 months following successful autotransplantation of premolar teeth moved from site 14 to 45 and from site 24 to site 35 
harvesting. ${ }^{[3]}$ Piezosurgery, which relies on ultrasound bone cutting, is associated with less thermal trauma to bone and its surrounding tissues when compared to traditional or conventional surgical techniques which rely on the use of rotating drills and a variety of saws. ${ }^{[10]}$ The fact that piezo-surgical instrumentation has no sharp edges, unlike conventional drills and saws, makes piezosurgery inherently safer. Piezosurgery uses copious irrigation to cool the ultrasonic tip which gently cuts the bone. The copious irrigation makes visualization easier than with conventional instrumentation.

\section{CONCLUSIONS}

Piezosurgical harvesting of donor autotransplant teeth results in the atraumatic preparation of a transplantable dental unit which is capable of becoming a functional autotransplanted tooth at its new alveolar recipient site.

\section{Acknowledgments}

The authors wish to acknowledge the University of Oulu for its support of this project.

\section{Financial support and sponsorship}

The authors wish to thank the EVO/VTR fund of the Oulu University Hospital for its generous financial support of this project.

\section{Conflicts of interest}

There are no conflicts of interest.

\section{REFERENCES}

1. Aizenbud D, Zaks M, Abu-El-Naaj I, Rachmiel A, Hazan-Molina H. Mandibular premolar autotransplantation in cleft affected patients: The replacement of congenital missing teeth as part of the cleft patient's treatment protocol. J Craniomaxillofac Surg 2013;41:371-81.

2. Andreasen JO, Schwartz O, Kofoed T, Daugaard-Jensen J. Transplantation of premolars as an approach for replacing avulsed teeth. Pediatr Dent 2009;31:129-32.

3. Gupta S, Goel M, Sachdeva G, Sharma B, Malhotra D. Autotransplantation. J Conserv Dent 2015;18:500-3.

4. Pavlíková G, Foltán R, Horká M, Hanzelka T, Borunská H, Sedý J. Piezosurgery in oral and maxillofacial surgery. Int J Oral Maxillofac Surg 2011;40:451-7.

5. Catros S, Montaudon M, Bou C, Da Costa Noble R, Fricain JC, Ella B, et al. Comparison of conventional transcrestal sinus lift and ultrasound-enhanced transcrestal hydrodynamic cavitational sinus lift for the filling of subantral space: A human cadaver study. J Oral Implantol 2015;41:657-61.

6. $\quad \mathrm{Li}$ J, Lee K, Chen H, Ou G. Piezoelectric surgery in maxillary sinus floor elevation with hydraulic pressure for xenograft and simultaneous implant placement. J Prosthet Dent 2013;110:344-8.

7. Purushotham S, Raveendran AM, Kripalani BK, D'Souza ML. Direct sinus lift and immediate implant placement using piezosurgical approach- a case report. J Clin Diagn Res 2016;10:ZD20-2.

8. Ma L, Mattheos N, Sun Y, Liu XL, Yip Chui Y, Lang NP, et al. Wound healing of osteotomy defects prepared with piezo or conventional surgical instruments: A pilot study in rabbits. J Investig Clin Dent 2015;6:211-20.

9. Echchadi ME, Benchikh B, Bellamine M, Kim SH. Corticotomy-assisted rapid maxillary expansion: A novel approach with a 3-year follow-up. Am J Orthod Dentofacial Orthop 2015;148:138-53.

10. Spinelli G, Mannelli G, Zhang YX, Lazzeri D, Spacca B, Genitori L, et al. Complex craniofacial advancement in paediatric patients: Piezoelectric and traditional technique evaluation. J Craniomaxillofac Surg 2015;43:1422-7. 